\title{
Mother and Self-Representations: Investigating Associations With Symptomatic Behavior and Academic Competence in Middle Childhood
}

\author{
Ariela Waniel and Beatriz Priel \\ Department of Behavioral Sciences, Ben-Gurion University of \\ the Negev, Israel
}

Avi Besser

Department of Behavioral Sciences, Sapir Academic

College, Israel

\begin{abstract}
This article reports two studies examining the content and structural aspects of maternal and self-representations in middle childhood in two prospective studies of 9 to 11-year-old children, their stability over time and interrelations, and their contribution to symptomatology and academic functioning. In Study $1(N=169)$, content and structural dimensions of participants' open-ended narratives of self and mother were assessed, and their factor structure was replicated across two consecutive measurement waves carried out a year apart. In Study 2

This article is based in part on Ariela Waniel's doctoral dissertation under the direction of Beatriz Priel, Department of Behavioral Sciences, Ben-Gurion University. This research was supported in part by the Research Advisory Board of the International Psychoanalytical Association. Grateful thanks are extended to the teachers and students who agreed to participate in this study.

We thank Robert F. Krueger and the anonymous reviewers for their constructive suggestions.

Correspondence concerning this article should be addressed to Beatriz Priel, Department of Behavioral Sciences, Ben-Gurion University of the Negev, Beer-Sheva 84105, Israel. Tel: 08-6472068. E-mail: bpriel@bgumail.bgu.ac.il.
\end{abstract}

Journal of Personality 74:1, February 2006

(C) 2005, Copyright the Authors

Journal compilation (C) 2006, Blackwell Publishing, Inc.

DOI: $10.1111 / \mathrm{j} .1467-6494.2005 .00374 . \mathrm{x}$ 
$(N=137)$, using an independent sample, the authors investigated the associations of self- and maternal representations with teachers' subsequent reports of children's internalizing and externalizing symptomatology and academic competence. It was assumed that dimensions of self-representations played a mediating role in the prediction of children's symptomatology and competence by their maternal representations. Results corroborated the existence of interdependent but distinct representations of self and mother in middle childhood, as well as the stability over time of the structural and thematic aspects within each representation. The content of the self- and maternal representations was found to associate with observed symptomatic behavior, while their structure associated with children's academic competence. In addition, results indicated that self-representation content mediates the association of maternal representation content with subsequent symptomatic behavior. Findings are discussed in the light of the differentiation and interdependence of selfand maternal representations in middle childhood.

In the present studies we address the relationships between self- and maternal representations in middle childhood and the role these two factors play in children's adjustment and behavior. In the first study, we examine whether children's internal representations of self and mother can be characterized by stable qualitative and structural attributes and in the second study, whether these attributes are meaningfully associated with children's subsequent symptomatology and academic competence. Consequently, we further explore the associations between maternal and self-representations, assuming that dimensions of selfrepresentations play a mediating role in the prediction of children's symptomatology and competence by maternal representations.

\section{Internal Representations as Basic Personality Constructs}

Three main theoretical frameworks-attachment, object relations, and social cognition - propose processes through which experiences in the relationships with significant others are organized and modeled into internal schemas or representations, which are conceptualized as developmental structures that guide subsequent interpersonal perception and functioning. Bowlby (1969, 1973, 1980) proposed the concept of internal working models of attachment that are assumed to include the subject's memories, perceptions, and expectations in relation to significant others as helpful and effective in diminishing distress. Advances in attachment research have shown 
that internal working models contained information about self, others, and their relationships and guided the processing of data and interpersonal behavior (Ainsworth, Blehar, Waters, \& Wall, 1978; Main, Kaplan, \& Cassidy, 1985). Moreover, the secure attachment style, based on positive internal working models of early relationships, has been found significantly to predict adaptive functioning (Fonagy \& Target, 1997; Hesse, 1999).

Social cognitive studies have examined regular patterns of interpersonal behavior or relational schemas, defined as including a selfschema, a schema for the other person, and a relational schema or interpersonal script (Baldwin, 1992; Baldwin \& Meunier, 1999). Studies of social cognition have shown increased interest in the function of relational schemas (Baldwin, 1992) or cognitive representations of self and significant others (Damon \& Hart, 1988; Rudolph, Hammen, \& Burge, 1995) in the processing of social information.

Object relations theories originated as an approach that centered on processes that constitute and mediate the individual's capacity for relatedness (e.g., Greenberg \& Mitchell, 1983). Object relations are conceptualized as motivational structures that guide perception and affect the organization of past experience and expectations. These internalized relationships are conceptualized as including representations of self, other, and their relationships and are assumed to influence processes of meaning attribution, encompassing interpersonal relationships, motivations, and attitudes. Self-representations reflect evolving processes leading to the formation of a realistic, differentiated, and positive sense of self-definition and identity. Parental representations are assumed to constitute developing templates for the capacity for mutual, satisfying, and attuned patterns of relationships with others (Blatt, Auerbach, \& Levy, 1997). Empirical evidence on internalizations of primary relational patterns has been reported for adolescents and adults (Blatt et al., 1997; Blatt, Brenneis, Schimek, \& Glick, 1976; Blatt \& Lerner, 1983); such findings have been corroborated in studies on the development of object representations in children populations (Priel, Kantor, \& Besser, 2000; Priel, Myodovnik, \& Rivlin-Beniaminy, 1995; Westen et al., 1991).

In spite of the different theoretical contexts and emphases, object relations, attachment, and social cognitive theories assume a basic interdependence between internal representations of parents and self. Both psychodynamic research with adults and attachment research with young children provide evidence of the importance of the linkage 
between internal representations of primary caregivers and the self, on one hand, and adaptive functioning and competence, on the other (Blatt, Auerbach, \& Aryan, 1998; Easterbrooks \& Abeles, 2000). In general, these studies assume that internal working models of a caring and reliable parent facilitate the construction of positive self-representations, while unpredictable or rejecting parental representations lead to the construction of negative representations of the self (Blatt, 2004; Blatt et al., 1997; Main et al., 1985). Furthermore, object relations empirical research underscores the importance of the interplay between the differentiation and relatedness between representations of self and caregiver during the entire life cycle (e.g., Blatt, Stayner, Auerbach, \& Behrends, 1996; for a recent extensive review see Blatt, 2004).

\section{Representations of Self and Parent in Middle Childhood}

The strength and quality of the relationships between parental and self-representations acquires primordial importance in the study of personality development in middle childhood and preadolescence. Empirical research addressing the study of internal representations in this developmental stage has shown that children seem to be processing their relationships with their parents and their self-individuation and autonomy in an interdependent manner (e.g., Hodges, Finnegan, \& Perry, 1999). This processing includes both a basic attachment to, as well as an increasing differentiation from, parental figures. Researchers on the social-cognitive tradition, point at the fundamental role played by attachment to parents during this stage, (Ryan, Stiller, \& Lynch, 1994; Toth \& Cicchetti, 1996). Ryan and Lynch (1989) defined attachment to parents as a positive developmental process that allows for autonomy in the context of ongoing support and reliance on the parental relationship. Detachment from parents, on the other hand, constitutes a manifestation of drawbacks in the ability to use the parental context as a supportive environment for the utilization of inner resources. Thus, within the framework of both object relations and social cognition theories, it seems plausible to assume that adjustment during middle childhood and early adolescence is related to moderate levels of association (or moderate levels of differentiation) between self- and parental representations. From this perspective we assume moderate correlations between dimensions of parent and self-representations, reflecting differentiation processes characteristic of this developmental stage. 
Even though the exploration of the separate, as well as conjoint, contributions of self- and parental representations to the prediction of children's adjustment and competence seems most significant for understanding personality developmental processes during middle childhood and adolescence, research on representations of relationships during this developmental period has mainly addressed selfand parental representations separately. Positive self-representations were found to associate with better behavioral adjustment and diminished symptomatology (Baumeister, 1990; Damon \& Hart, 1988; King, Naylor, Segal, Evans, \& Shain, 1993; Segal \& Blatt, 1993) and children's representations of relationships were reported to correlate with adjustment in middle childhood (Allen, Hauser, Eickholt, Bell, \& O'Connor, 1994; Baldwin, 1992; Frank, Pirsch, \& Wright, 1990). In addition, a study by Ryan and colleagues (1994) centered upon the relations between representations of significant others and a specific aspect of the self: self-esteem. Thus, little is known about the relationships between basic aspects of representations of both parent and self and their separate and conjoint contributions to psychological adjustment and competence in middle childhood.

The studies to be presented here intend to approach the separate and conjoint associations between self- and parental representations and psychological adjustment and competence in middle childhood. We approached this question assuming that children's representation of self is experienced in the light of their internal representations of the parent. This perspective reflects Cooley's (1902) and Mead's (1934) basic idea about the "looking-glass-self," whose construction is based primarily on the incorporation of the regard of significant others and is akin to conceptualizations of the "self-other complementarity" proposed by Bowlby (1969). Contemporary psychoanalytic conceptualizations also underscore the organizing function of parental representations of relationships in the formation of the sense of self (Stern, 1985). Accordingly, we expected children's parental representation to associate with their self-representation, which, in turn, was expected to correlate with behavioral outcomes.

\section{The Assessment of Self- and Parental Representations}

The empirical study of mental representations has led to the development of assessment techniques that supplement direct self-report instruments and aim at elucidating important aspects of the 
representation of self and significant others. Representations tend to include conscious content as well as organizational principles, which are less accessible to conscious thought (Main et al., 1985, Bretherton, 1990). Furthermore, representations of self and of significant others are not seen as accurate reflections of real events but as patterns of mental activation that might include defensive distortions (Bretherton \& Munholland, 1999). Narrative techniques, based on open-ended responses to significant stimuli, try to address these unique characteristics of mental representations in their assessment procedure. One such measure, initially designed for adult and adolescent populations, is the Object Relations Inventory (ORI), a narrative technique for the assessment of qualitative and structural dimensions of object representations (Blatt, Chevron, Quinlan, Schaffer, \& Wein, 1992; Blatt, Wein, Chevron, \& Quinlan, 1979). This assessment technique is based on open narratives by individuals about parents or significant others. In addition, a complementary technique, the Coding of Self-Descriptions (CSD), was developed for the assessment of representations of self in adult populations (Blatt, Bers, \& Schaffer, 1993).

The ORI and CSD narratives provide an experience-near account of self and significant others. A major aspect of this technique is the differentiation made between content and structural aspects of mental representations, a procedure that has also been followed by other researchers of child development (see Shields, Ryan, \& Cicchetti, 2001). Whereas the qualitative dimension is assumed to capture children's caretaking experiences and the affective tone of parent-child relationships, the structural dimension is assumed to reflect the representation's basic cognitive organizing principles. This is a core distinction between the phenomenological characteristics of the described figure, or of the self, and the organizational and regulatory principles involved in these representations. In children's descriptions of significant others, narrative content seems to capture perceptions of parent's degree of benevolence, care, and supportive involvement (Shields et al., 2001; Westen et al., 1991), as well as the degree of criticism and punitiveness exerted by the parent (Westen et al., 1991). Narrative structural aspects include the complexity level through which the parent is perceived (Bretherton, 1990; Main et al., 1985) as well as the description's degree of integration or coherence (Fonagy, 1996; Westen et al., 1991). The developmental dimensions of the model have been empirically confirmed (Priel et al., 1995), and important associations 
were found between dimensions of parental representations and measures of self-perception and peer evaluation in a population of children (Avery \& Ryan, 1988; Priel, in press; Priel et al., 1995).

This conceptualization of the main dimensions of content and structure of internal representations is congruent with reported empirical differential associations between these dimensions and aspects of adjustment in middle childhood: While the structural aspects of maternal representations were found to be strongly related to children's cognitive development in normal populations (Avery \& Ryan, 1988, Priel, Besser, Waniel, Yonas-Segal \& Kuperminc, in press), significant associations were found between content aspects of parental representation and measures of socioemotional adjustment in middle childhood (Priel, Kantor et al., 2000; Segal, Westen, Lohr, \& Silk, 1993). These findings suggest that (a) a more caring parental representation and more positive self-feelings associate with better interpersonal functioning and self-regulation, and (b) more mature and complex representations of self and parent associate with children's cognitive capacities and academic performance.

Narrative contents of children's self-descriptions seem to center around the aspect of self-regard or self-worth (Harter, 1990a), including the degree of competence and agency attributed to the self (Sroufe, 1990) as well as the degree to which the self is experienced as accepted and loved by others (Blatt \& Bers, 1993). Structural aspects uniquely characteristic of the description of self include the degree of reflectivity or introspection through which the subject is observing itself (Fonagy \& Target, 1997; Harter, 1990b) as well as the diversity or variability of self roles included in the description (Gergen, 1991). The use of the CSD in adult populations has corroborated the existence of basic content and structural factors (Blatt et al., 1993; Blatt et al., 1996), showing self-description factors significantly to differentiate psychiatric patients from nonpatients (Bers, Blatt, Sayward, \& Johnston, 1993) and reporting significant relationships between aspects of the self-description and measures of depression (Blatt \& Bers, 1993). It has not yet been determined, however, whether the CSD technique is equally effective in elucidating the content and structure of children's self-representation and whether children's representations will exhibit a factor profile that is similar to that exhibited by adults. The exploration of the content and structure of children's self-representations using this semistructured narrative technique is an important extension of the present study. 
Findings from studies on parental and self-representations reinforce the relationship between narrative descriptions of self and parent and outcome measures related to change and healthy functioning. They do not, however, directly address the self- and parental narratives' differential input and association with adjustment outcomes. In the present study we intend to address this question directly by testing the confirmation of a theoretically based model of the interrelationships between children's self- and maternal representations and adjustment. Using a parallel narrative assessment technique for both self- and parental descriptions, we are interested in verifying the structure and content of these representations and expect them to be differentially related to children's behavior beyond shared method variance.

\section{Overview of Present Studies' Aims and Hypotheses}

Our research had three main objectives. (1) The first was to explore the areas of association between the content and structure of maternal and self-representations and the consistency of these assessments and their associations over time in middle childhood. (2) We then hoped to verify empirically the assumption that in middle childhood the qualitative aspects of internal representations associate with children's adjustment, while the structural aspects of internal representations are linked to children's cognitive capacities. We were interested in studying these associations when the representation and adjustment measures were assessed from independent sources, thus controlling for shared source and method variance. (3) In accordance with theory and empirical findings addressing a basic interdependence between the internal representation of parents and the self during this developmental stage, we aimed at exploring the assumption that self-representations might mediate the associations between maternal representations and children's outcomes.

We conducted two studies. In Study 1 we confirmed the structure and content of children's maternal and self-representations and the associations between them and provided evidence of the reliability and consistency over time for these representational measures. In Study 2 we examined basic associations between the maternal and self-representational measures and symptomatic behavior and academic competence and tested the mediating role of self-representa- 
tions in the prediction of children's symptomatic behavior and academic competence by maternal representations.

Our specific hypotheses were the following:

Hypothesis 1 (H1): Attributes of maternal and self-representations will converge into coherent factors that will be discriminable as content or structural aspects of the representation.

Hypothesis 2 (H2): Content and structural factors of self- and maternal representations are assumed to be consistent over measurement time.

Hypothesis 3 ( $\boldsymbol{H 3})$ : Attributes of maternal and self-representations will be significantly, though moderately, correlated.

Hypothesis 4 (H4): Contents of maternal and self-representations at Time 1 were assumed to predict children's symptomatic behavior, as reported by the teacher at Time 2. Structural aspects of maternal and self-representations at Time 1 were assumed to predict children's academic competence, as reported by the teacher at Time 2 .

Hypothesis 5 ( $\boldsymbol{H 5}$ ): The content dimensions of self-representations were assumed to mediate the relationship between the content of maternal representations and children's symptomatic behavior. The structural dimensions of self-representations were assumed to mediate the relationship between the structure of maternal representations and academic competence.

\section{STUDY 1}

In Study 1 we verified the structure and content dimensions of both maternal and self- representations and explored for the first time the stability of these constructs over a period of 1 year. A demonstration of relative stability in the content and structure dimensions of selfand mother representations in middle childhood would allow subsequent exploration of their assumed associations with children's patterns of behavior.

\section{Participants and Procedure}

Participants were a sample of 169 children, from an Israeli urban, middle-class population, aged 9 to 11 upon entering the study $(M=10.2 ; S D=0.64)$. The 91 girls and 78 boys participating in the study were recruited from three regular elementary schools, after 
approval of the Israeli Ministry of Education Ethics Committee was obtained. Participants were eligible to participate in the study only after obtaining written, informed parental consent, in accordance with the Ethics Committee guidelines. Eighty-five percent of the parents and children approached consented to take part in the study. Children were interviewed individually in their school setting in a quiet and private classroom provided by the school faculty. Interviews were conducted in Hebrew. Children in the present sample were interviewed once within the 6 first weeks of the school year and again within the 6 first weeks of the consecutive school year. In the present study the attrition rate was $7.1 \%$ of the children who were interviewed in the first wave of measurement. Participants who dropped out in the second wave did so mainly due to change of domicile.

\section{Method}

\section{Interview and Coding Procedures}

Interviewers and raters were recruited and trained especially for this project. Four specially trained interviewers were randomly assigned to children in the two measurement waves. The interviewer was presented to the children by the homeroom teacher in each class, after which the interviewer gave an explanation and asked the children to take part in a study about "children's thoughts and feelings concerning themselves and significant others." These semistructured interviews were designed to obtain open-ended, spontaneous descriptions of self and significant others. The children were interviewed separately on mother and on self in random order. After creating a comfortable atmosphere and rapport, participants were asked to tell about their mother or self, with no further specification. After each spontaneous description, the interviewer encouraged the children in a nondirective way to expand their response (e.g., "Is there something else you would like to tell about Mom/yourself?"). The spontaneous answers to these questions constituted the narrative that was coded. Participants were further probed if there were aspects of the description that were unclear or ambiguous. Answers to probes were not coded in themselves but used only to help coding the spontaneous descriptions.

Four independent trained raters rated the maternal descriptions. Four other independent raters rated the self-descriptions. Each maternal or self-description was coded by two of the four possible raters on the basis of random pairing, so that descriptions were randomly assigned to one of the six possible pair combinations. Descriptions were coded for each indicator separately, raters being blind to the expected factor structure and the study's aims. 


\section{Measures}

Maternal representations. We evaluated children's maternal representations using an adaptation of the Object Representation Inventory (ORI), a procedure devised by Blatt and colleagues for the evaluation of adult and adolescent representations of significant others (Blatt et al., 1992). Previous research has shown the reliability and validity of the ORI with children's samples (Avery \& Ryan, 1988; Besser \& Kantor, 2000; Priel, in press; Priel et al., 2000; Priel, Melamed-Hass, Priel et al., 1995; Priel, Seksig-Bitton, Waniel, Myodovnik, \& Rosen, 2002).

The following eight categories, devised to capture central qualitative aspects of the maternal representation, were used for the coding of children's descriptions (Priel et al., 2002): Affectionate, Malevolent-Benevolent, Cold-Warm, Constructive Involvement, Nurturant, Weak-Strong, Judgmental and Punitive. The first five categories address aspects related to the degree of benevolence attributed to the maternal figure, ranging from descriptions of an uninvolved and uncaring maternal figure to a warm and benign one (for ranges of scales and their meaning, see Appendix A). The remaining two categories, Judgmental and Punitive, address the degree to which the maternal figure is experienced as threatening and disapproving, ranging from descriptions of a nonpunitive and acceptant maternal figure to a punishing and highly critical one (see Appendix A). In addition, two categories, Conceptual Level and Degree of Integration, devised to capture central structural aspects of the maternal representation, were used for the coding of children's descriptions. These categories address the extent to which the description is well integrated and includes internal-state attributes, regardless of the description's content (see Appendix A).

Four independent raters, blind to the subjects' self-descriptions, rated all maternal descriptions. The Inter-Rater Intraclass correlation reliability coefficients (Shrout \& Fleiss, 1979) for each of the 10 categories ranged from .88 to .94 . When scores were not identical, the mean score was utilized. The categories of Malevolent-Benevolent and Degree of Integration were found to have a low variance of responses (more than $95 \%$ of the sample obtained scores of 5 or 2 , respectively, by two independent raters) within the scale, and were thus not included in the confirmatory model for the Maternal Representation measure (for criteria, see Tinsley \& Tinsley, 1987).

Self-Representations. We adapted Blatt and colleagues' (Blatt et al, 1993) coding procedure of open-ended self-descriptions for use with children. This adaptation includes changes and new categories that were developed on the basis of the following sources: (a) the Manual for the Coding of Self-Descriptions in Adult Populations - CSD (Blatt et al., 1993); (b) 
theoretical assumptions addressing content and structural attributes of children's self-representations (Damon \& Hart, 1988; Harter, 1986; Marsh \& Hattie, 1996); and (c) the content analysis of 60 self-descriptions collected in a pilot sample in search of categories relevant for coding at this age group.

The following four categories, devised to capture central qualitative aspects of the representation of self, were found relevant for the coding of children's descriptions (Priel et al., 2002): Felt Security, Cold-Warm, Competence, and Agency. These categories address aspects related to the extent to which the self is experienced as worthy and loved, ranging from negative descriptions involving critical and devaluating self-feelings to positive descriptions involving warm and competent feelings towards the self (for ranges of scales and their meaning, see Appendix B). In addition, two categories, Reflectivity and Substantiality, devised to capture central structural aspects of the representation of self, were found relevant for the coding of children's descriptions. These categories address the extent to which the self-description is diverse and reflective, regardless of the description's content.

Four independent raters, blind to the subjects' maternal descriptions, rated all self- descriptions. The Inter-Rater Intraclass correlation reliability coefficients (Shrout \& Fleiss, 1979) for each of the six self-description scales ranged from .82 to .96 . When scores were not identical, the mean score was utilized.

\section{Results}

Data analyses involved the confirmation (Confirmatory Factor Analysis [CFA]) of the hypothesized qualitative and structural factors of the self- and maternal representation constructs. In the CFA analyses we specified the scales' scores obtained from the child's open-ended descriptions as indicators of latent constructs of selfand maternal representations, respectively. In the present study, two assessments of self- and maternal representations were collected a year apart. Accordingly, the measurement model defined also allowed testing for consistency of the factor structures (test/retest).

The factor structure and consistency of assessments of self- and maternal representations. Structural Equation Modeling (SEM) (e.g., Byrne, 2001; Hoyle, 1995) was used to test the hypothesized associations between the measures of self- and maternal representations and the underlying theoretical constructs in a sample of 169 children, 
for whom two assessment waves of the representational measures were conducted a year apart. Using AMOS 4.0 (Arbuckle, 1999), which is based on the variance-covariance matrix, we tested the adequacy of measurement models and the fit of the structural models, using maximum-likelihood estimations. In evaluating the overall goodness-of-fit for the SEM models, the following criteria were used: (a) the chi-square $\chi^{2} p$-value, which traditionally is $p>.05$, indicates that there are no statistically significant discrepancies between the observed data and the hypothesized model; ${ }^{1}$ (b) the Robust Comparative Fit Index (CFI; Bentler, 1990) and the Goodness of Fit Index (GFI; Jöreskog, \& Sörbom, 1985) -indices that adjust for the sample size (for the CFI and GFI, a cutoff of 0.90 is generally accepted as indicating a good fit, where 1.0 indicates a perfect fit); (c) the Root Mean Square Error of Approximation (RMSEA; Browne \& Cudeck, 1993), a value of less than 0.05 indicates a good fit. A table presenting the means, standard deviations, and intercorrelations between the study variables is available upon request from the first author.

Since our hypothesized model assumes self- and maternal representations to be distinct but associated constructs, a single CFA model including both constructs in both assessment times would be the most accurately representative of this assumption. However, such a model would involve a large number of observed indicator variables ( 28 observed variables as can be seen in Figures $1 \mathrm{a}$ and $\mathrm{b}$ ) and parameters to be estimated, which because of the present sample size, would result in significantly lowered statistical power and low chances for obtaining model convergence.

Given the present study's stress on defining and verifying the hypothesized constructs and their fit to the empirical data and while

1. Although a nonsignificant $p$ value has traditionally been used as a criterion for not rejecting on SEM, this criterion is overly strict and sensitive for models with numerous variables (Kelloway, 1998). Therefore, we also used alternate criteria that reflect real-world conditions. We have chosen to accept a model in which the chi square divided by the degrees of freedom ratio is $\leq 2$ and in which the $C F I$ and GFI and are greater then 0.90 and for the $R M S E A$, an adequately fitting model will have an RMSEA index between 0.00 and 0.06 with confidence intervals between 0.00 and 0.08 ( $\mathrm{Hu} \&$ Bentler, 1998, 1999). These moderately stringent acceptance criteria will clearly reject inadequate or poorly specified models, while accepting for consideration models that meet real-world criteria for reasonable fit and representation of the data (Kelloway, 1998). 
(a)

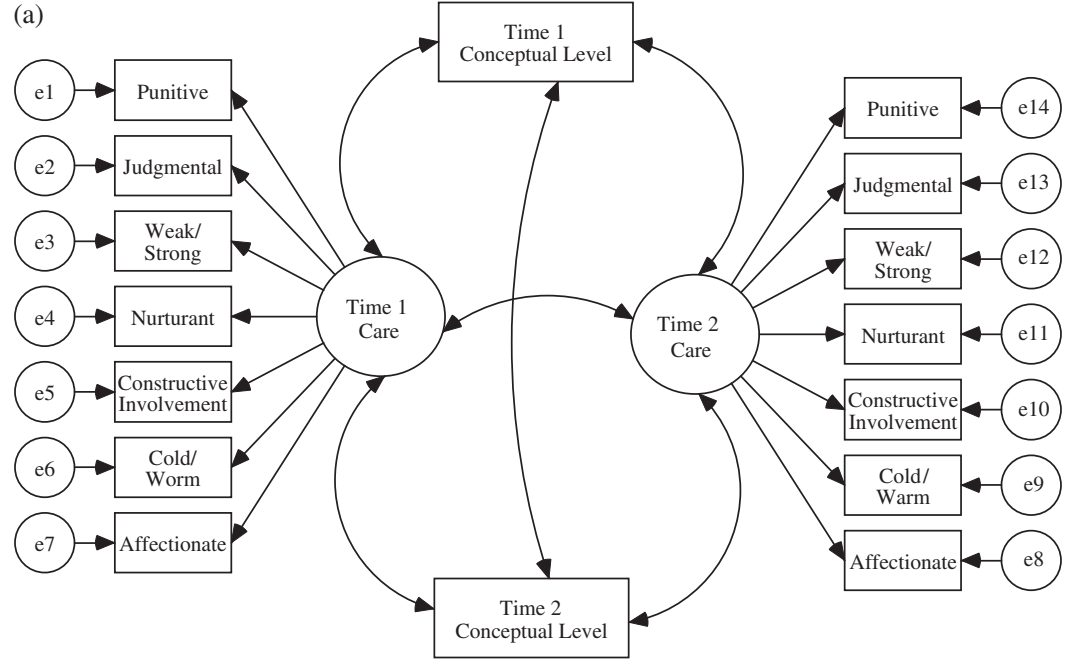

(b)

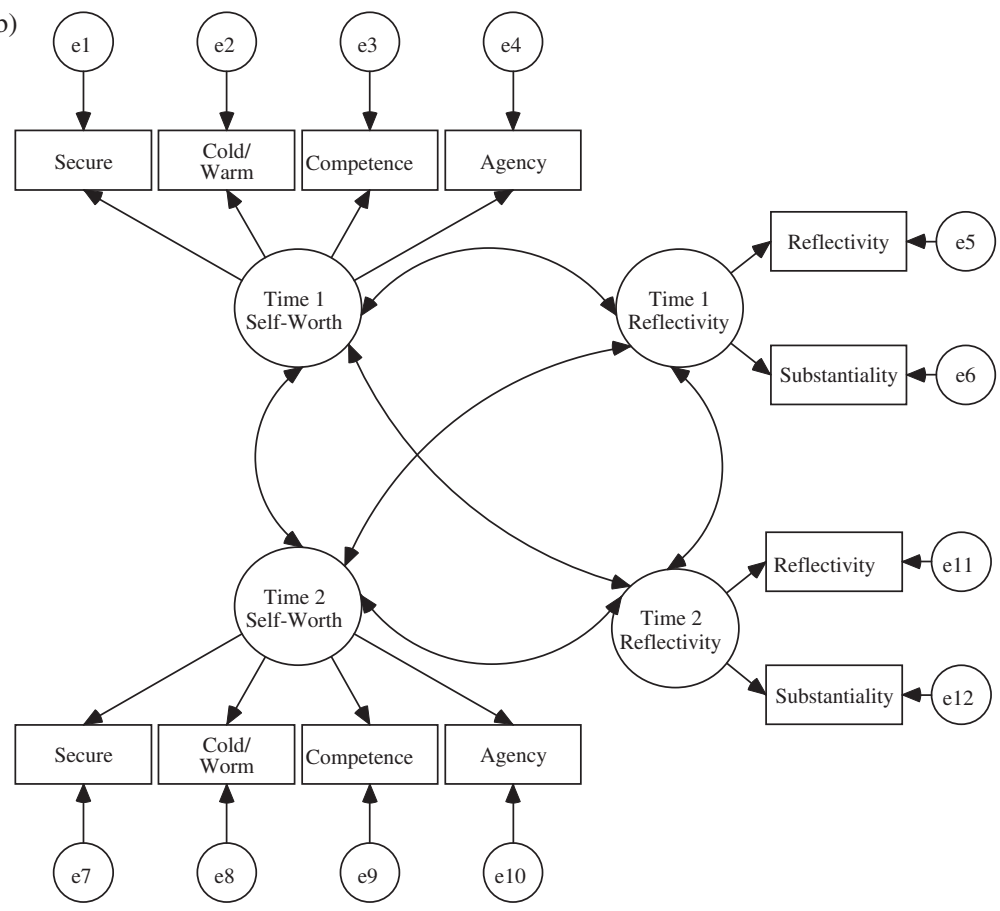

Figure 1

Illustration of CFA measurement for ( $\alpha$ ) Parsimonious Maternal Representation Model and (b) Self-Representation Model.

Note. To simplify the presentation the auto-correlations among the measurement errors of the same observed indicators in the two assessment times of the latent constructs were omitted. 
keeping the above limitations in mind, we first confirmed self- and maternal representation constructs simultaneously for both times each in a separate CFA model. In order to be able to test for maternal and self-representations together while still preserving an appropriate number of observed variables, we then tested self- and maternal representations in a joint model separately for each assessment time. The additional benefit of such an approach is the ability to test for the replicability of the associations among the defined constructs.

Maternal representations. We tested a measurement model depicting the hypothesized factor structure of the maternal representation constructs in the study's two assessment waves, which were carried out a year apart. We defined a measurement model (CFA) that included three factors: Benevolence and Punitiveness - specified as latent constructs composed of their respective scales' scores - and Conceptual Level - specified as an observed indicator composed of its scale's score. The five scales composing the Benevolence factor (Affectionate, Cold-Warm, Constructive Involvement, Nurturant, Weak-Strong) assess a qualitative dimension related to the extent to which the maternal figure is experienced as benign and giving. These same scales were found to converge reliably into one factor defined as Benevolence in adult and adolescent samples (Blatt et al., 1997; Blatt et al., 1992). The two scales composing the Punitiveness factor (Punitiveness and Judgemental) assess a qualitative dimension referring to the degree to which the maternal figure is experienced as threatening and punitive. A similar factor was reliably found in adult samples (Blatt et al., 1992). The observed variable-Conceptual Level - is composed of a single structural scale (Conceptual Level) reflecting the degree to which the maternal representation is conceptually developed.

In our measurement model, the constructs of Benevolence and Punitiveness, as well as the Conceptual Level indicator, were tested simultaneously for Time 1 and Time 2, delineating all the intercorrelations between them, while controlling for the autocorrelations among the measurement errors of the same observed measures in the two assessment times. This allowed us to confirm the hypothesized constructs simultaneously for both times and to estimate within each construct the test/re-test association, thus obtaining a measure of its test-retest reliability, consistency, and stability. The hypothesized 
model also allowed for comparisons of association magnitudes between the constructs in the two assessment waves. In addition, the model includes the specification of one error covariance (between the error terms of Nurturant and Cold-Warm), which was needed in order to account for greater shared uniqueness between two specific attributes within the Benevolence construct of the Maternal Representation (Jöreskog \& Sörbom, 1985).

The specified measurement model was found to produce the following plausible fit indices to observed data: $\chi^{2}[90, N=169]=120.6$, $\chi^{2} / d f=1.3, p=.02, C F I=.96, G F I=.92, R M S E A=.04$. In this mod$\mathrm{el}$, all the factor indicators and path loadings were substantial and statistically significant in the expected directions. Factor loadings ranged between .35 and .91 .

The test/re-test associations between the latent constructs in the two measurement waves were found to be significant and substantial (for Benevolence1 and Benevolence2, $r=0.54, t=4.44, p<0.0001$; for Punitiveness1 and Punitiveness2, $r=0.66, t=4.70, p<0.0001$; and for Conceptual Level1 and Conceptual Level2, $r=0.34$, $t=4.170, p<.0001)$.

Although the above model was found to fit the data well, we were interested in testing the acceptability of a competing measurement model based on the conceptual and theoretical distinction between structure and content of the representation. In this model, Benevolence and Punitiveness were conceptualized as content attributes of the maternal representation and were expected to be inversely loaded on one content factor. We termed this latent construct "Care," reflecting the assumption that the maternal figure is described as benevolent and caring through the scales composing the Benevolence factor and as lacking in benevolence and care through the scales composing the Punitiveness factor. This theoretical assumption is further strengthened by the distinctively high correlation found between the Benevolence and Punitiveness latent constructs in each measurement wave in the above-tested model $(r=-.55$ and -.32 respectively; the correlations between the Conceptual Level indicator and the constructs of Benevolence and Punitiveness within each measurement wave were nonsignificant, ranging between .01 and .19). It is important to note here that a similar factor structure was found using the coding procedure of Blatt et al., (1992) in a revised principal components analysis of maternal representations of 279 undergraduates (Heck \& Pincus, 2001), where the Judgmental and 
Punitiveness scales were found to be inversely loaded together with the Benevolence scales on a single factor. This theoretically based model is more parsimonious as well as reflective of our assumption that benevolence and punitiveness are qualitative characteristics dependently attributed to the parent at this developmental stage (Tinsley \& Tinsley, 1987).

The more parsimonious Maternal Representation model (see Figure 1a) was also found to produce plausible fit indices to the observed data $\left(\chi^{2}[99, N=169]=128.8, \chi^{2} / d f=1.3, \quad p=.02\right.$, $C F I=.95, G F I=.92, R M S E A=.04)$, with all the factor indicators and path loadings statistically significant in the expected directions (see Table 1 under Study 1 column). In this model, the Punitiveness scale is significant but not substantially loaded on the maternal content factor, reflecting the low variance of this observed scale in a normal population of children where very little direct reference is made to actual punishing behavior by the parent. The model seems to show that threatening aspects of the parent are expressed mainly through the child's description of her as judgmental and as low in benevolence. When modifying the model by excluding the Punitiveness scale, no significant fit difference was found. We therefore did not exclude the scale, since it was still shown to load significantly on the content factor.

Self-representations. We tested a measurement model (CFA) depicting the hypothesized factor structure of the self-representation constructs in the study's two assessment waves. We defined a measurement model that included two factors - Self-Worth and Reflectivity- specified as latent constructs composed of the scores of their respective scales. The four scales (Felt Security, Cold-Warm, Competence, Agency) composing the first factor, labeled Self-Worth, reflect the qualitative dimension of self-representation, i.e., the degree to which the self is experienced as competent and worthy. The two scales (Reflectivity and Substantiality) composing the second factor, labeled Reflectivity, reflect the structural dimension of self-representations, i.e., the degree to which the self-representation is well integrated and reflective. The constructs of Self-Worth and Reflectivity were tested simultaneously for Time 1 and Time 2, delineating all intercorrelations between them, while controlling for the autocorrelations among the measurement errors of the same observed measures in the two assessment times. The model also includes the specification of one error covariance (between 


\section{Table 1}

Parsimonious Maternal Representation Model

\begin{tabular}{lllc}
\hline & \multicolumn{2}{c}{ Study 1 } & Study 2 \\
\hline Variables & Care 1 & Care 2 & Care \\
\hline Affectionate & $.48^{* *}(.23)$ & $.47^{* *}(.22)$ & $.51^{* *}(.25)$ \\
Cold-Warm & $.67^{* * *}(.45)$ & $.63^{* *}(.40)$ & $.63^{* *}(.40)$ \\
Constructive Inv. & $.76^{* *}(.58)$ & $.64^{* *}(.41)$ & $.75^{* *}(.56)$ \\
Nurturant & $.75^{* *}(.56)$ & $.65^{* *}(.43)$ & $.69^{* *}(.48)$ \\
Weak-Strong & $.73^{* *}(.53)$ & $.61^{* *}(.37)$ & $.68^{* *}(.46)$ \\
Judgmental & $-.30^{* *}(.09)$ & $-.30^{* *}(.09)$ & $-.57^{* *}(.32)$ \\
Punitive & $-.16^{*}(.03)$ & $-.13^{*}(.02)$ & $-.24^{*}(.06)$ \\
\hline
\end{tabular}

Note.

$* p<.03 ; * * p<.0001$.

() indicate the shared variance value.

the error terms of Felt Security and Cold-Warm), which was needed in order to account for greater shared uniqueness between two specific attributes within the Self-Worth construct of the Self-Representation ( Jöreskog \& Sörbom, 1985).

The measurement model specified (see Figure $1 \mathrm{~b}$ ) was found to fit the observed data well $\left(\chi^{2}[45, N=169]=70.3, \chi^{2} / d f=1.6, p=.01\right.$, $C F I=.97, G F I=.94, R M S E A=.04)$. Table 2 (under Study 1 column) shows the loadings of the observed indicators on their respective constructs. As can be seen, all the factor indicators and path loadings coefficients were substantial and statistically significant in the expected directions.

The test/re-test associations between the latent constructs in the two measurement waves were found to be significant and substantial (for Self-Worth1 and Self-Worth2, $r=0.46, t=3.84, p<.0001$; and for Reflectivity1 and Reflectivity2, $r=0.71, t=4.36, p<.0001$ ).

Self- and maternal representations: Joint models. We tested a joint self- and maternal representation measurement model (CFA) depicting the hypothesized factor structure of the self-representation (the latent variables: Reflectivity and Substantiality) and maternal representation (the Care latent variable, and the observed Conceptual Level variable) constructs (see Figure 1a and b) separately for each assessment wave. 


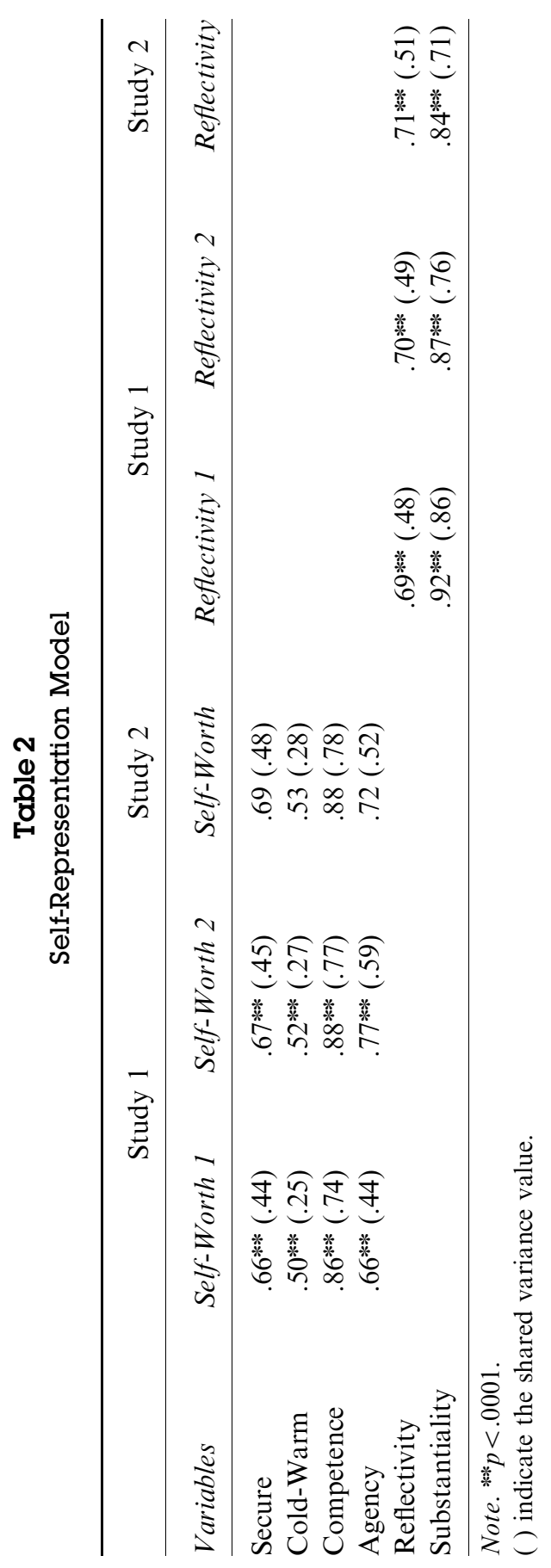


The measurement model specified for the associations between self- and maternal representation constructs at Time 1 was found to fit the observed data well $\left(\chi^{2}[70, N=169]=89.8, \chi^{2} / d f=1.3\right.$, $p=.06, C F I=.97, G F I=.93$, RMSEA $=.04)$. The measurement model specified for the associations between self- and maternal representation constructs at Time 2 resulted with the following plausible fit indices $\left(\chi^{2}[70, N=169]=143, \chi^{2} / d f=2.0, p=.001, C F I=.91\right.$, $G F I=.92, R M S E A=.05)$. Results of the joint model for each assessment time indicated that the path coefficients and loadings of the observed indicators on their respective constructs, as presented in Table 1 and 2 (under Study 1 column), were not altered. The correlations between Care and Self-Worth were positive and significant $(.48, t=3.16, p<.0001$, and $.54, t=3.42, p<.001$ at Time 1 and Time 2, respectively). The correlations between Conceptual Level and Reflectivity were positive and significant $(.38, t=3.98, p<$ .0001 , and $.48 t=4.47, p<.0001$ at Time 1 and Time 2, respective1y). These correlations confirm the expected associations between the qualitative dimensions of self- and maternal representations, on the one hand, and between their structural dimensions, on the other. It is important to note, however, that alternative CFA models evaluating the possibility that the self- or maternal representation content or structure is subsumed into one common construct did not fit the data. Thus, although the content and structure of the self- and mother representations are correlated, these representations are distinct constructs.

\section{Discussion}

The results of Study 1 provide evidence for the content and structural dimensions of both the self- and the maternal representations. The content, or qualitative dimension, seems to center on representations of the mother's benevolence and the self's worth. The structural domain is composed of the Conceptual Level of maternal representations and the degree of integration and awareness of interpretation of the self-representation. The significant correlations between the two assessment times not only represent significant testretest reliability but also serve as indications of construct structure, validity, and stability, as well as its replicability over time. Moreover, this study's results have shown that these significant aspects of 
children's internal representations of self and mother can be reliably measured and replicated across measurement times.

The findings suggest that positive contents of maternal representations might relate to the children's basic experience of having, in Bowlby's words, trusted others "standing behind them" (Bowlby, 1973, p. 25), which might lead to a basic self-reliance, as assessed by the Self-Worth construct of the self-representations. As to the structural factors, the Conceptual Level of maternal representations and the Reflectivity factor of self-representations convey the complexity and cognitive sophistication of the representations.

The findings of Study 1 suggest a possible differentiation within the assumed continuity between attributions of maternal and selfrepresentations along two lines: the interpersonal affective line (Care and Self-Worth), on the one hand and the inner resources-cognitive dimension line (Conceptual Level and Reflectivity) on the other. While interpersonal affective aspects of the representations may be theoretically linked with affect regulation, their structural dimensions associate with children's cognitive performance. Consequently, we assumed that the thematic factors of the representations might predict children's emotional adjustment, while the structure of the mother and self-representations might predict their ability to use their cognitive resources. In order to explore these assumptions, we conducted a second study.

\section{Study 2}

In Study 2, using an independent sample, we investigated the associations between the self- and maternal representation constructs and symptomatic behavior and academic competence. The main aim of this study was to explore the contribution of the content and structure dimensions of self- and mother representations by testing their association with children's symptoms and their academic competence. Warm and caring maternal representations were assumed to associate with representations of the self as more worthy and with better adjustment and less symptomatology. Maternal representations with higher Conceptual Level scores were assumed to associate with more reflective and complex self-representations, thus facilitating the use of inner resources such as children's academic competence.

In order to estimate these associations longitudinally, we assessed adjustment and cognitive competence 10 months after the assessment 
of the representations. Moreover, we used measures of representation, on the one hand, and measures of symptomatic behavior and academic competence, on the other, that were assessed from different sources (child and teacher, respectively) and so were methodologically independent. We then tested the hypotheses that the content of children's self-representation would mediate the association between the content of maternal representation and symptomatic behavior and that the structure of children's self-representations would mediate the association between the Conceptual Level of maternal representations and children's academic competence.

An additional aim of this study was methodological: we were interested in testing in a different sample the replicability of the content and structure of children's self- and maternal representations obtained in Study 1.

\section{Method}

\section{Participants}

Participants in Study 2 were a sample of 137 children from an Israeli urban, middle-class population, aged 9 to 11 upon entering the study $(M=10.3 ; S D=0.59)$. The 66 girls and 71 boys participating in the study were recruited from two regular elementary schools after approval of the Israeli Ministry of Education Ethics Committee was obtained. Participants were allowed in the study only after obtaining written parental informed consent, in accordance with the Ethics Committee guidelines. Ninety-one percent of the parents and children approached consented to take part in the study. Children were interviewed individually in their school setting in a quiet and private classroom provided by the school faculty.

The child's homeroom teacher completed the Teacher Report Form (TRF; Achenbach, 1991) 10 months after the children were interviewed. The nine homeroom teachers participating in the study were given detailed instructions for the completion of the checklist, specifically concerning the scaling of symptom gravity, with a research assistant present for questioning during completion.

\section{Interview and Coding Procedures}

The collection and coding of the descriptions was standardized and carried out by four trained interviewers and four raters according to the detailed protocol included in the instruments' manuals (Priel et al., 2002; Priel et al., 2003) and described in detail in Study 1. 


\section{Measures}

Maternal representations. The adapted $O R I$ described in Study 1 was utilized for the assessment of maternal representations. The Inter-Rater Intraclass correlation reliability coefficients (Shrout \& Fleiss, 1979) for the maternal description scales in the present sample ranged from .88 to 95. When scores were not identical, the mean score was utilized. The estimated alpha reliability for the Care factor was .81 .

Self-representations. The adapted version of the CSD described in Study 1 was again used to assess self-representations. The Inter-Rater Intraclass correlation reliability coefficients (Shrout \& Fleiss, 1979) for the self-description scales in the present sample ranged from .87 to .97 . When scores were not identical, the mean score was utilized. The estimated alpha reliability for the Self-Worth factor was .89. In addition, the "Item-Scale" Pearson correlations between the Reflectivity factor and its two scales were .92 and .81 , for the Reflectivity scale and the Substantiality scale, respectively.

Symptomatic behavior. We assessed children's symptomatology by means of teachers' reports of behavioral and emotional problems, using the Externalizing and Internalizing Problems scales of Achenbach's Teacher Report Form (TRF; Achenbach, 2001), a standardized teacher-report questionnaire designed to assess behavioral problems in children between 5 and 18 years. The Externalizing Problems factor of the TRF includes the presence of delinquent and aggressive behavior. The Internalizing Problems factor of the TRF relates to withdrawn, anxious-depressed, and somatic complaints. The TRF has high concurrent validity (above .80) and associates significantly with the Diagnostic and Statistical Manual of Mental Disorders criteria (Achenbach, 2001; American Psychiatric Association, 1994). The TRF has been adapted to use with Israeli children (Zilber, Auerbach, \& Lerner, 1994). In the present study, we obtained internal consistency coefficients Cronbach's alpha scores of .70 and .70 for the Externalizing and Internalizing Problems scales, respectively.

Academic competence. We assessed children's academic performance by means of teachers' reports of a child's achievement in the Mathematics, Language, and Studying scales of the TRF.

\section{Results}

\section{Analytic Strategy}

We first tested the associations between the content and structural constructs of the Maternal Representation (Care and Conceptual 
Level) and of the Self-Representation (Self-Worth and Reflectivity) measured in Time 1, with Symptomatic Behavior and Academic Competence measured 10 months later. After confirming significant associations between aspects of self-and mother representations and levels of symptomatology and academic competence, we proceeded to test hypotheses regarding the relative contribution of the maternal and self-representations in their association with Time 2 symptomatic behavior and academic competence.

A table presenting the means, standard deviations, and intercorrelations between the study variables is available upon request from the first author.

Structural Models: Self- and Maternal Representations in the Prediction of Symptomatology and Academic Competence

Maternal representation and symptomatology. Following Anderson and Gerbing's advice (1988), before testing a structural model, we defined a measurement model that included the Maternal Representation constructs assessed in Time 1 and a latent construct of Symptomatic Behavior assessed 10 months later. In accordance with the parsimonious Maternal Representation model (demonstrated in Study 1), we defined a measurement model that included the Care construct (specified by its 7 indicators), the Conceptual Level observed indicator, and a latent construct of Symptomatic Behavior, which was defined using subjects' internalizing and externalizing scores as its indicators. The specified measurement model was found to fit the observed data well $\left(\chi^{2}[32, N=137]=40.9, \chi^{2} / d f=1.3\right.$, $p=0.13, C F I=.97, G F I=.95, R M S E A=.04)$, with all the factor indicators and path loadings found to be substantial and statistically significant in the expected directions (see Table 1 under Study 2 column). Specifically, the symptomatology construct was found to explain $29 \%$ and $72 \%$ of the internalizing and externalizing indicators, respectively, with path coefficients of .53 and $.85(p<.0001)$.

We then defined a structural model in which the Care construct and Conceptual Level indicator assessed in Time 1 were specified as predictors of the Symptomatology construct assessed in Time 2, which served as the dependent criterion (regression with latent constructs). The Symptomatology Structural Maternal Representation Model was found to fit the observed data well $\chi^{2}[32, N=137]=$ $\left.40.9, \chi^{2} / d f=1.3, p=.13, C F I=.97, G F I=.95, \quad R M S E A=.04\right)$. 
In this model, the path coefficient from Care to Symptomatic Behavior was found to be significant $\beta=-.28, t=-2.43, p=.01$ ), while the path coefficient from Conceptual Level was found to be nonsignificant $\beta=-.15, t=-1.53$, ns.). The model explained $10 \%$ of the variance in Symptomatic Behavior.

Self-representation and symptomatology. Again before testing a structural model, we defined a measurement model that included the Self-Representation constructs assessed in Time 1 and a latent construct of Symptomatic Behavior assessed 10 months later. We therefore defined a measurement model that included the SelfWorth construct (specified by its 4 indicators), the Reflectivity construct (specified by its 2 indicators) as demonstrated in Study 1 , and a latent construct of Symptomatic Behavior, which was defined using subjects' internalizing and externalizing scores as its indicators. The measurement model specified was found to fit the observed data welll $\left(\chi^{2}[16, N=137]=28.2, \chi^{2} / d f=1.8, p=.03\right.$, $C F I=.96, G F I=.95, R M S E A=.05)$, with the factor indicators and path loadings found to be substantial and statistically significant in the expected directions (see Table 2 under Study 2 column). The Symptomatic Behavior construct loadings were .57 and .79 $(p<.0001)$ for the internalizing and externalizing indicators, respectively.

We then defined a structural model in which the Self-Worth and Reflectivity constructs assessed in Time 1 were specified as predictors of the Symptomatology construct, assessed in Time 2, which served as the dependent criterion (regression with latent constructs). The Symptomatology Structural Self-Representation Model was found to fit the observed data well $\left(\chi^{2}[16\right.$, $N=137]=28.2, \quad \chi^{2} / d f=1.8, \quad p=.03, \quad C F I=.96, \quad G F I=.95$, $R M S E A=.05)$, with all the factor indicators found to be statistically significant in the expected directions. In this model, the path coefficient from Self-Worth to Symptomatic Behavior was found to be significant $(\beta=-.32, t=-2.08, p=.03)$, while the path coefficient from Reflectivity was found to be nonsignificant $(\beta=-.12$, $t=-.84, n s$.) The model explained $15 \%$ of the variance in Symptomatic Behavior.

In sum, only the content dimensions of mother and self-representations at Time 1 were found to associate with Symptomatology at Time 2 . 
Maternal representations and academic competence. We hypothesized that the structural factors of the self- and maternal representations would significantly associate with children's Academic Competence, while no such association would be found for the content factors. We therefore tested the two structural models defined above (one for the Maternal and one for the Self-Representation), changing the dependent criterion from Symptomatic Behavior to Academic Competence. A latent construct of Academic Competence was specified using subjects' math, language, and studying scores as its indicators.

We defined a structural model in which the Maternal Care construct and Conceptual Level indicator assessed in Time 1 were specified as predictors of the Academic Competence construct assessed in Time 2. The Academic Competence Structural Maternal Representation Model specified was found to fit the observed data well $\left(\chi^{2}[41\right.$, $N=137]=63.5, \chi^{2} / d f=1.5, \quad p=.01, \quad C F I=.97, \quad G F I=.93$, $R M S E A=.05)$, with the factor indicators and path loadings found to be substantial and statistically significant in the expected directions. Specifically, the Academic Competence latent construct was found to explain $96 \%, 84 \%$, and $72 \%$ of the mathematics, language, and overall study performance indicators, respectively, with respective path coefficients of $.98, .92$, and .85 . In this model, the path coefficient from Conceptual Level to Academic Competence was found to be significant $(\beta=.18, t=2.07, p=.03)$, while the path coefficient from Care was found to be nonsignificant $(\beta=.16$, $t=1.70, n s$.). The model explained $6 \%$ of the variance in Academic Competence.

Self-representations and academic competence. We defined a structural model in which the Self-Worth and Reflectivity constructs assessed in Time 1 were specified as the predictors of the Academic Competence construct, assessed in Time 2. The specified Academic Competence Structural Self-Representation Model was found to fit the observed data well $\left(\chi^{2}[23, N=137]=37.4, \chi^{2} / d f=1.6, p=0.03\right.$, $C F I=.98, G F I=.94, R M S E A=.05)$, with the factor indicators and path loadings found to be substantial and statistically significant in the expected directions. The Academic Competence factor loadings ranged from .97 to .72 , and path coefficients ranged from .85 to .98 . In this model, the path coefficient from Reflectivity to Academic Competence approached significance $(\beta=.22, t=1.89, p=.06$, 
one-tailed $=.03$ ), while the path coefficient from Self-Worth was found to be nonsignificant $(\beta=.16, t=1.53, n s$.). The model explained $10 \%$ of the variance in Academic Competence.

In sum, the structural dimensions of maternal representations were found to associate with Academic Competence. The association of the structural dimensions self-representations with Academic Competence did approach significance.

When examining specific associations between each of the content and structural dimensions of the self- and maternal representations and mathematics, language, and overall study performance, an interesting pattern emerges that further elucidates the Academic Competence Structural Models' results. While the Maternal Conceptual Level and the Self-Reflectiveness and Substantiality dimensions have significant correlations with the three academic performance scales (correlations ranging from .18, $p=.03$ to $.30, p=.005$ ), most of the self- and maternal representations' content dimensions do not have significant correlations with these criteria. Two content dimensions, however, were found to significantly correlate with the academic performance scales: the Punitiveness scale of the maternal representation was found to be inversely correlated with mathematics and language performance scales $(r=.17, p=.04$, and $r=.22, p=.009$, respectively) and the Competence scale of the self-representation was found to positively correlate with mathematics, language, and study performance scales $(r=.25, p=.004, r=.26, p=.003$, and $r=.23$, $p=.006$, respectively).

Testing mediation. In order to explore the hypothesis that the SelfRepresentation mediates the Maternal Representation's association with Symptomatic Behavior, we followed Baron and Kenny's (1986) criteria for testing mediation models. Given the Structural Models' results showing that only the content constructs of both the self- and the maternal representations had significant associations with consecutive Symptomatic Behavior, we used Maternal Care and SelfWorth in our mediation analysis.

To establish mediation, we first confirmed the existence of a significant direct relation between Maternal Care and Self-Worth, thus testing the association between the predictor and the mediator constructs. This model was found to fit the observed data well $\left(\chi^{2}[41\right.$, $N=137]=64.1, \quad \chi^{2} / d f=1.5, \quad p=.01, \quad C F I=.95, \quad G F I=.92$, $R M S E A=.05)$, with Maternal Care found to be significantly associ- 
ated with Self-Worth $(\beta=.33, t=2.86, p<.001)$, explaining $11 \%$ of the Self-Worth variance. We then proceeded to confirm the Maternal Care construct's direct relation to Symptomatic Behavior, thus testing the association between the independent and criterion constructs (This relationship has already been established in the structural Maternal Representation Model, but we wanted to confirm its significance without controlling for its shared variance with the Conceptual Level indicator, which was found to be nonsignificantly related to Symptomatology and thus irrelevant in the present analysis). This model was found to fit the observed data well $\left(\chi^{2}[25, N=137]=\right.$ 21.9, $\left.\chi^{2} / d f=0.9, p=.64, C F I=1.0, G F I=.97, R M S E A=.00\right)$, with Maternal Care found to be significantly associated with decreased levels of Symptomatic Behavior $(\beta=-.25, t=-2.38, p=0.02)$, explaining 7\% of the Symptomatic Behavior variance.

Finally, in order to establish mediation, we tested whether the indirect relation between Maternal Care and Symptomatic Behavior (criterion) through Self-Worth (mediator) significantly reduced the Maternal Care construct's (predictor) direct relation to the criterion. We therefore specified a model (see Figure 2) in which the Maternal Care construct was defined to have both a direct path to Symptomatic Behavior and an indirect one through Self-Worth. This model was found to fit the observed data well $\left(\chi^{2}[60, N=137]=86.7, \chi^{2} /\right.$ $d f=1.4, p=.01, C F I=.95, G F I=.92, R M S E A=.05)$, with the significant direct path from Maternal Care to Symptomatic Behavior now found to be nonsignificant $(\beta=-.15, t=-.97, n s$.), while both paths from Maternal Care to Self-Worth and from Self-Worth to Symptomatic Behavior were found to be significant in the expected direction $(\beta=.32, \quad t=2.90, \quad p=.005 ; \quad$ and $\beta=-.33$, $t=-2.55, p=0.01$, respectively). The decrease in the coefficient of the direct path from Maternal Care to Symptomatic Behavior, once the indirect effect through Self-Worth was controlled, was significant according to Sobel's test (Baron \& Kenny, 1986): $Z=1.99$, $p<.05$. This model was found to explain $17 \%$ of the Symptomatic Behavior variance. In sum, the content dimensions of self-representations were found to mediate the relationship between the maternal representations content and symptomatic behavior.

We also hypothesized that the structural aspects of selfrepresentations will mediate the maternal representation's Conceptual Level prediction of Academic Competence. However, our initial results didn't meet Baron and Kenny's (1986) criteria for 

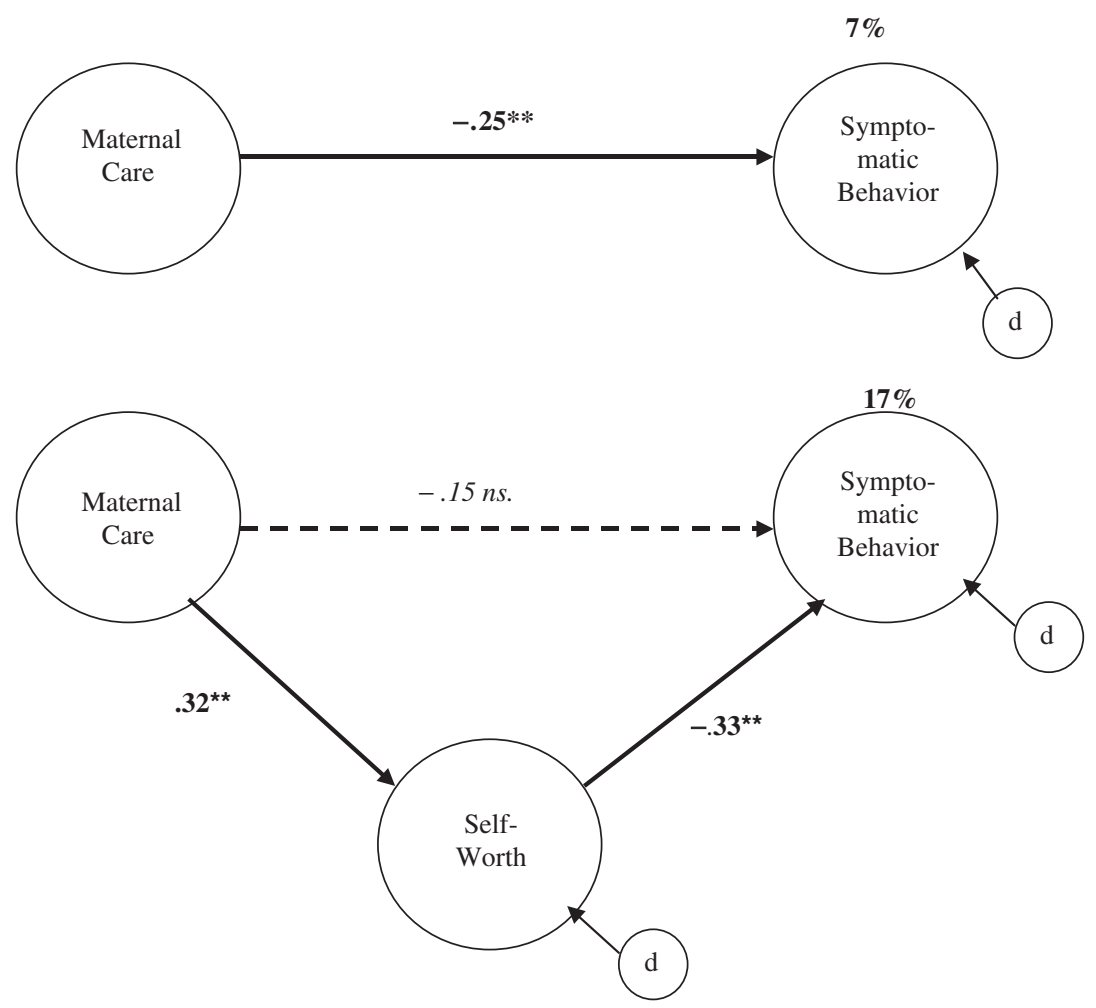

Figure 2

The direct effects of Maternal Care on Symptomatic Behavior (7\% of the variance; see top) and the mediational effect of Self-Worth (adding a significant $10 \%$ to the variance explained; see bottom) on the association between Maternal Care and Symptomatic Behavior.

Note. ${ }^{* *} p<.0001$

Large circles represent latent constructs. Small circles (d) reflect disturbances. A percentage above endogenous criterion variable represents the amount of variance explained $\left(R^{2}\right)$. Unidirectional arrows depict hypothesized directional, or "causal," links. Standardized maximum likelihood parameters are used. Bold estimates are statistically significant as determined by critical ratios. As can be seen, Self-Worth mediated the effect of Maternal Care on Symptomatic Behavior and added a significant $10 \%$ to the prediction of Time 2 Symptomatic Behavior.

mediation (i.e., the association of the mediator with the criteria variable only approached significance); as can be seen above, the path coefficient from Reflectivity to Academic Competence approached significance. 


\section{Discussion}

The results of Study 2 provide evidence for the replicability in a new sample of the assessments of content and structure of self- and maternal representations, as obtained in Study 1. In addition, this study's results show that the content, but not the structure, of both maternal and self-representations is significantly associated with children's symptomatic behavior. Our results provide evidence for a mediation model of the relation between the maternal and the selfrepresentation contents in the association with adjustment: SelfWorth was found to mediate the association between Maternal Care and consecutive Symptomatic Behavior.

Our findings reveal significant associations between the structural dimensions of both maternal and self-representations and children's Academic Competence. The structural dimensions of self-representations, however, were not found to mediate the relationship between the maternal representations structure and Academic Competence. Moreover, content categories of the maternal representation (Punitiveness) and of self-representation (Competence) were significantly associated with Academic Competence. Thus, children's competence at school during middle childhood associates with their levels of representations organization, as well as with their belief in their inner resources and their expectation of a facilitating environment.

\section{GENERAL DISCUSSION}

The two studies presented here confirmed the factor structure of children's representations of self and mother, their stability over time, their replicability in a new sample, and their predictive validity. The confirmation of the expected factorial structure allowed for the exploration of the convergence effects of self- and mother representations' content and structure in their association with symptomatology and academic competence, respectively. Our studies' results suggest that content and structural dimension of self- and mother representations play distinct roles in the explanation of individual differences among school-age children. Moreover, our findings point to the necessity of looking at the reciprocal effects of aspects of selfand maternal representations at this stage.

The replicability of the constructs of self- and maternal representations in two measurement times and in two samples shows these 
constructs to be relatively stable and possibly trait-like in middle childhood. This finding is indicative of the methodological consistency of the assessment measures, but it also supports conceptualizing children's internal representations as having a relatively stable core or a characteristic structure and qualitative level of experiencing, rather than as predominantly colored by momentary feelings or circumstances. Such a conceptualization is in line with developmental socialcognitive studies showing that the ability to construe and maintain a generalized concept of self-worth is achieved in middle childhood (Harter, 1990a). Moreover, during school years, children have been found to think of others mainly in terms of unitary traits and stable characteristics, contrary to younger children's more situational and gratification-based interpersonal representations (Harter, 1988).

Our measurement model of the maternal representation has shown that there is little reference to the presence of negative attributes in these representations, as indicated by the relatively lower loadings of the Punitive and Judgmental categories on the representation's content construct. These loadings might indicate that, in a normal population of children at this developmental stage, it is the lack of positive contents, rather than the presence of negative ones in the parental representation, that seems to play a maladaptive role. Our finding is also congruent with social-cognitive studies documenting that normal children in middle childhood tend to represent self and significant others in a socially desirable and overly positive manner (Harter, 1990b). Such a tendency seems to be developmentally adaptive, as opposed to findings showing that in samples of maltreated children, it is the presence of negative contents in the representations of self (Toth, Cicchetti, Macfie, \& Emde, 1997) and mother (Manashko \& Priel, 2004) that associates directly with symptomatic behavior. Contents reflecting punitive and critical aspects of maternal representations in normal populations might convey experiences of external control and lack of age-appropriate autonomy.

Our examination of the relations between the maternal and the self-representations in the association with symptomatic behavior was a first step in the study of these representations' differential contribution to children's adjustment. In spite of shared method variance, self- and mother representation constructs were found to be only moderately correlated, thus emphasizing their being related but distinct constructs. Moreover, this finding stressed the necessity of assessing these constructs separately and then examining the 
relations between them and their respective contributions to the prediction of outcomes.

The mediation model that was confirmed-where the content of self-representation was found to mediate the prediction of symptomatic behavior by the degree of the maternal representation's benevolence - reaffirmed the interdependence of these representations, on the one hand, and their differentiated function in the association with children's adjustment, on the other. This finding supports Baldwin's (1992) contention about the central importance of relational schemas; i.e., schemas of self in relation to an other, rather than of the self or the other person in isolation (p. 461). Our mediation model is also akin to the concept of internal working models, for example, Horowitz's (1989, p. 260) "schemas of self in interaction with another person," and Hill and Safran's (1994) emphasis on the relationships between representations of self and other.

Our studies' findings show that the self mediates the association between maternal representations and behavioral outcomes long after the effects of primary caretaking experiences on the formation of self have been exerted. The significant negative direct associations found between the Maternal Care construct and subsequent Internalizing and Externalizing symptoms endorse basic assumptions of attachment and object relations theories about the fundamental role played by representations of primary caregivers as responsive and available in children's self-regulation of behavior (Stern, 1985; Van Ijzendoorn \& Bakermans-Kranenburg, 1996). These findings support a model of personality development where accessible and supportive maternal representations facilitate the construction of a complementary representation of the self as valued and competent, which, in turn, secures self-regulation and adjustment.

The structure of both maternal and self-representations has been found to associate significantly with academic competence. Without excluding the plausibility of the effects of children's intelligence levels on these variables, our findings imply that children with more differentiated, complex, and reflective internal representations are more able to internalize the required school behavior and adaptively use their cognitive capacities. The associations found between academic competence and both structural and content dimensions of maternal representations, however, emphasize the extent to which school assets are affected both by children's cognitive complexity and their expectations from interpersonal relationships. Our findings 
indicate that children's levels of academic performance also associate with lower Punitiveness scores of maternal representations, on the one hand, and higher Competence scores of self-representations, on the other. This pattern of associations confirms the importance of primary relationship patterns for children's academic performance (e.g., Jacobsen \& Hofmann, 1997). Moreover, the association between Academic Competence and the maternal representation Punitiveness and self-representation Competence factors suggests that school-age children's engagement with the academic environment is affected beyond their cognitive sophistication by perceptions of low external control and of self as competent. These results confirm previous findings about the basic role that autonomous self-regulation plays in middlechildhood academic adjustment (Grolnick \& Ryan, 1989).

The hypothesized mediation role of the structural dimensions of self-representations on children's academic competence was not confirmed in this research, suggesting a different model of association from the one confirmed vis-à-vis symptomatology. The lack of results stems from the weak association revealed between the structural aspect of the self-representation (Reflectivity) and the construct of Academic Competence; a plausible explanation of this finding is that this variable taps basic organization principles of interpersonal rather than academic functioning.

Among the strengths of the present research was the application of several restrictions to the assessment of the parental and self-representation measures and on the examination of their associations with symptomatic behavior. In the effort to assess reliably the representations' constructs, we first demonstrated their stability and replicability, and only then examined their predictive validity in a new sample. When examining associations with maladjustment in a new sample, we assessed symptomatic behavior from an external source, and in an independent and consecutive measurement wave, thus controlling for the possibility of inflated correlations between the representational constructs and symptomatology due to shared source or method variance. Finally, the importance of using an assessment method that is not based on direct self-report for the measure of hypothetical constructs such as internal representations should be noted. The procedure devised by Blatt and colleagues (1992, 1993) allows for subjects' spontaneous nondirected narrative in response to standard stimuli while implementing a quantitative coding method that allowed for the systematic examination of individual differences. 
Despite these strengths, at least four caveats should guide the interpretation of our studies' findings. First, we evaluated only maternal representations; evaluations of the effect of paternal representations might add considerably to the proposed models. Second, although our design included two consecutive measurement waves, it was not long-term enough to allow for univocal causal inferences; therefore, one could still argue that existent patterns of symptomatology might have affected aspects of children's self- and maternal representations. To clarify this issue, future research should focus on causal models using long-term longitudinal designs. It is plausible that such a design might show a transactional model of the effects of internal representations and behavior where each variable affects and is affected by the other. Third, even though teachers' reports of children's behavior are a reasonable criterion, other assessments of children's behavior and feelings (i.e., sociometric evaluations, direct observations, parent and peer reports) may shed additional light on the characteristics and implications of the model proposed. Finally, our findings do not definitely exclude "third factor" explanations of the associations revealed. Children's intellectual quotient and even their socioeconomic status could underlie the association between structural aspects of mental representations and academic competence. In addition, temperamental characteristics could explain both the qualitative aspects of maternal and self-representations on the one hand, and children's capacities for self-regulation on the other.

\section{REFERENCES}

Achenbach, T. M. (1991). Manual for the Teacher's Report Form and 1991 profile. Burlington: University of Vermont, Department of Psychiatry.

Ainsworth, M. D. S., Blehar, M. C., Waters, E., \& Wall, S. (1978). Patterns of attachment: A psychological study of the strange situation. Hillsdale, NJ: Erlbaum.

Allen, J. P., Hauser, S. T., Eickholt, C., Bell, K. L., \& O’Connor, T. G. (1994). Autonomy and relatedness in family interactions as predictors of expressions of negative affect. Journal of Research on Adolescence, 4, 535-552.

American Psychiatric Association. (1994). Diagnostic and statistical manual of mental disorders (4th ed). Washington, DC: Author.

Anderson, J. C., \& Gerbing, D. W. (1988). Structural equation modeling in practice: A review and recommended two-step approach. Psychological Bulletin, 103, 411-423.

Arbuckle, J. L. (1999). AMOS: A structural equation modeling program. Chicago: Small Waters. 
Avery, R. R., \& Ryan, R. M. (1988). Object relations and ego development: Comparison and correlates in middle childhood. Journal of Personality, 56, 547-569.

Baldwin, M. W. (1992). Relational schemas and the processing of social information. Psychological Bulletin, 112, 461-484.

Baldwin, M. W., \& Meunier, J. (1999). The cued activation of attachment relational schemas. Social Cognition, 17, 209-227.

Baron, R. M., \& Kenny, D. A. (1986). The moderator-mediator variable distinction in social psychological research: Conceptual, strategic, and statistical considerations. Journal of Personality and Social Psychology, 51, 1173-1182.

Baumeister, R. F. (1990). Suicide as escape from self. Psychological Review, 97, 90-113.

Bentler, P. M. (1990). Comparative fit indexes in structural models. Psychological Bulletin, 107, 238-246.

Bers, S. A., Blatt, S. J., Sayward, H. K., \& Johnston, R. S. (1993). Normal and pathological aspects of self-descriptions and their change over long-term treatment. Psychoanalytic Psychology, 10, 17-37.

Blatt, S. J. (2004). Experiences of depression: Theoretical, clinical, and research perspectives. Washington, DC: American Psychological Association.

Blatt, S. J., Auerbach, J. S., \& Aryan, M. (1998). Representational structures and the theraputic process. In R. F. Bornstein \& J. M. Masling (Eds.), Empirical studies of the theraputic hour (ch. 3). Washington DC: American Psychological Association.

Blatt, S. J., Auerbach, J. S., \& Levy, K. N. (1997). Mental representations in personality development, psychopathology, and the therapeutic process. $R e-$ view of General Psychology, 1, 351-374.

Blatt, S. J., \& Bers, S. A. (1993). The sense of self in depression: A psychodynamic perspective. In Z. Segal \& S. J. Blatt (Eds.), The self in emotional distress: Cognitive and psychodynamic perspectives (pp. 171-210). New York: Guilford Press.

Blatt, S. J., Bers, S. A., \& Schaffer, C. E. (1993). The assessment of self descriptions. Unpublished manual. New Haven, CT: Yale University.

Blatt, S. J., \& Blass, R. B. (1990). Attachment and separateness: A dialectic model of the products and processes of development throughout the life cycle. The Psychoanalytical Study of the Child, 47, 107-127.

Blatt, S. J., \& Blass, R. B. (1995). Relatedness and self-definition: A dialectic model of personality development. In G. G. Noam \& K. W. Fischer (Eds.), Development and vulnerabilities in close relationships (pp. 309-338). Hillsdale, NJ: Erlbaum.

Blatt, S. J., Brenneis, C. B., Schimek, J. G., \& Glick, M. (1976). Normal development and psychopathological impairment of the concept of the object on the Rorschach. Journal of Abnormal Psychology, 85, 364-373.

Blatt, S. J., Chevron, E. S., Quinlan, D. M., Schaffer, C. E., \& Wein, S. (1992). The assessment of qualitative and structural dimensions of object representations (Rev. ed). Unpublished manual. New Haven, CT: Yale University.

Blatt, S. J., \& Lerner, H. D. (1983). The psychological assessment of object representation. Journal of Personality Assessment, 47, 7-28. 
Blatt, S. J., Stayner, D. A., Auerbach, J. S., \& Behrends, R. S. (1996). Change in object and self-representations in long-term, intensive, inpatient treatment of seriously disturbed adolescents and young adults. Psychiatry, 59, 82-107.

Blatt, S. J., Wein, S. J., Chevron, E., \& Quinlan, D. M. (1979). Parental representations and depression in normal young adults. Journal of Abnormal Psychology, 38, 388-397.

Blatt, S. J., Wiseman, H., Prince-Gibson, E., \& Gatt, C. (1991). Object representations and change in clinical functioning. Psychotherapy, 28, 273-283.

Bornstein, R. F., \& O’Neil, R. M. (1992). Parental perceptions and psychopathology. Journal of Nervous and Mental Disease, 180, 475-483.

Bowlby, J. (1969). Attachment and loss: Attachment. New York: Basic Books.

Bowlby, J. (1973). Attachment and loss: Separation, anxiety and anger. New York: Basic Books.

Bowlby, J. (1980). Attachment and loss: Loss. New York: Basic Books.

Bretherton, I. (1990). Open communication and internal working models: Their role in the development of atachment relationships. In R. Thompson (Ed.), Nebraska Symposium on Motivation: Vol. 36. Socioemotional development (pp. 39-113). Lincoln: University of Nebraska Press.

Bretherton, I., \& Munholland, K. A. (1999). Internal working models in attachment relationships: A construct revisited. In: J. Cassidy \& P. R. Shaver (Eds.), Handbook of attachment theory, Research and clinical applications (pp. 89-114). New York: The Guilford Press.

Browne, M. W., \& Cudeck, R. (1993). Alternative ways of assessing model fit. In I. K. A. Bollen \& J. S. Long (Eds.), Testing structural equation models (pp. 136162). Newbury Park, CA: Sage.

Byrne, B. M. (2001). Structural equation modeling with AMOS. Hillsdale, NJ: Lawrence Erlbaum Association.

Cooley, C. H. (1902). Human nature and social order. New York: Scribner's.

Damon, W., \& Hart, D. (1988). Self-understanding in childhood and adolescence. New York: Cambridge University Press.

Easterbrooks, M. A., \& Abeles, R. (2000). Windows to the self in 8-year olds: Bridges to attachment representation and behavioral adjustment. Attachment and Human Development, 2, 85-106.

Fonagy, P. (1996). The significance of the development of metacognitive control over mental representations in parenting and infant development. Journal of Clinical Psychoanalysis, 5, 67-86.

Fonagy, P., \& Target, M. (1997). Attachment and reflective function: Their role in self organization. Development and Psychopathology, 9, 679-700.

Frank, S. J., Pirsch, L. A., \& Wright, V. C. (1990). Late adolescents' perceptions of their relationships with their parents: Relationships among de-idealization, autonomy, relatedness, and insecurity, and implications for adolescent adjustment and ego identity status. Journal of Youth and Adolescence, 19, $571-589$.

Gergen, K. J. (1991). The saturated self. New York: Basic Books.

Greenberg, J. R., \& Mitchell, S. A. (1983). Object relations in psychoanalytic theory. Cambridge, MA: Harvard University Press. 
Griffin, D., \& Bartholomew, K. (1994). Models of the self and other: Fundamental dimensions underlying measures of adult attachment. Journal of Personality and Social Psychology, 67, 430-445.

Grolnick, W. S., \& Ryan, R. M. (1989). Parent styles associated with children's self-regulation and competence in school. Journal of Educational Psychology, 81, 143-154.

Gruen, R. J., \& Blatt, S. J. (1990). Change in self and object representation during long-term dynamically oriented treatment. Psychoanalytic Psychology, 7, 399422.

Harter, S. (1986). Processes underlying the construction, maintenance, and enhancement of the self-concept in children. In J. Suls \& A. G. Greenwald (Eds.), Psychological perspectives on the self (Vol. 4, pp. 137-181). Hillsdale, NJ: Lawrence Erlbaum Association.

Harter, S. (1988). Developmental and dynamic changes in the nature of the selfconcept: Implications for child psychotherapy. In S. Shirk (Ed.), Cognitive development and child psychotherapy (pp. 119-160). New York: Plenum Press.

Harter, S. (1990a). Causes, correlates, and the functional role of global self-worth: A life-span perspective. In J. Kolligian \& R. Sternberg (Eds.), Perceptions of competence and incompetence across the life-span (pp. 67-98). New Haven, CT: Yale University Press.

Harter, S. (1990b). Developmental differences in the nature of self-representations: Implications for the understanding, assessment, and treatment of maladaptive behavior. Cognitive Therapy and Research, 14, 113-142.

Heck, S. A., \& Pincus, A. L. (2001). Agency and communion in the structure of parental representations. Journal of Personality Assessment, 76, 180-184.

Hesse, E. (1999). The Adult Attachment Interview: Historical and current perspectives. In J. Cassidy \& P. R. Shaver (Eds.), Handbook of attachment: Theory, research, \& clinical applications (pp. 395-433). New York: The Guilford Press.

Hill, C. R. (1994). Assessing interpersonal schemas: Anticipated responses of significant others. Journal of Social and Clinical Psychology, 13, 366-379.

Hodges, V. E., Finnegan, R. A., \& Perry, D. (1999). Skewed autonomy-relatedness in preadolescents' conceptions of their relationship with mother, father and best friend. Developmental Psychology, 35, 737-748.

Horowitz, M. J. (1989). Relationship schema formulation: Role-relationship models and intrapsychic conflict. Psychiatry: Journal for the Study of Interpersonal Processes, 52, 260-274.

Hoyle, R. H. (1995). Structural equation modeling: Concepts, issues, and applications. Thousand Oaks, CA: Sage.

Hu, L. T., \& Bentler, P. M. (1998). Fit indices in covariance structure modeling: Sensitivity and underparamaterized model misspecification. Psychological Methods, 3, 424-453.

Hu, L. T., \& Bentler, P. M. (1999). Cutoff criteria for fit indexes in covariance structure analysis: Conventional criteria versus new alternatives. Structural Equation Modeling, 6, 1-55.

Jöreskog, K. G., \& Sörbom, D. (1985). LISREL VI: Analysis of linear structural relationships by the method of maximum likelihood. Mooresville, IN: Scientific Software. 
Jacobsen, T., \& Hofmann, V. (1997). Children's attachment representations: Longitudinal relations to school behavior and academic competency in middle childhood and adolescence. Developmental Psychology, 33, 703-710.

Kelloway, E. K. (1998). Using LISREL for structural equation modeling: A researcher's guide. Newbury Park, CA: Sage.

King, C. A., Naylor, M. W., Segal, H. G., Evans, T., \& Shain, B. N. (1993). Global self-worth, specific self-perceptions of competence, and depression in adolescents. Journal of the American Academy of Child and Adolescent Psychiatry, 32, 745-752.

Main, M., Kaplan, N., \& Cassidy, J. (1985). Security in infancy, childhood and adulthood: A move to the level of representation. In: I. Bretherton \& E. Waters (Eds.), Growing points in attachment: Theory and research (Monographs of the Society for Research in Child Development, Serial 209 (pp. 66-104). Chicago: University of Chicago Press.

Manashko, S., \& Priel, B. (2004). Maltreated children's representations of mother and substitute caregiver: Effects on externalizing symptoms (submitted for publication).

Marsh, H. W., \& Hattie, J. (1996). Theoretical perspectives on the structure of self-concept. In B. A. Bracken (Ed.), Handbook of self-concept (pp. 38-90). New York: Wiley.

Mead, G. H. (1934). Mind, self, and society. Chicago: University of Chicago Press.

Priel, B. (in press). Representations in middle childhood: A dialogical perspective. In: J. S. Auerbach, K. N. Levy, \& C. E. Shaffer (Eds.), Relatedness, self-definition, and mental representation: Essays in honor of Sidney J. Blatt. New York: Bruner-Routledge Press.

Priel, B., Besser, A., Waniel, A., Yonas-Segal, M., \& Kuperminc, D.(in press). Interpersonal and intrapersonal processes in the formation of maternal representations in middle childhood: Review, new findings and future directions. Israel Journal of Psychiatry.

Priel, B., Kantor, B., \& Besser, A. (2000). Two maternal representations: A study of Israeli adopted children. Psychoanalytic Psychology, 17, 128-145.

Priel, B., Melamed-Hass, S., Besser, A., \& Kantor, B. (2000). Adjustment among adopted children: The role of maternal self-reflectiveness. Family Relationships, 49, 389-396.

Priel, B., Myodovnick, E., \& Rivlin-Beniaminy, N. (1995). Parental representations among preschool and fourth-grade children: Integrating object relational and cognitive developmental frameworks. Journal of Personality Assessment, 65, 372-388.

Priel, B., Seksig-Bitton, I., Waniel, A., Myodovnik, E., \& Rosen, G. (2002). Manual for the coding of parental representations among children (Hebrew). Unpublished manuscript. Beer-Sheva, Israel: Ben-Gurion University of the Negev, Behavioral Sciences Department.

Priel, B., Waniel, A., Yones, M., Seksig-Bitton, I., Weinberg, B., \& Zerach, G. (1993). Manual for the coding of self representations among children. Unpublished manuscript. Beer-Sheva, Israel: Ben-Gurion University of the Negev, Behavioral Sciences Department. 
Rudolph, K. D., Hammen, C., \& Burge, D. (1995). Cognitive representations of self, family, and peers in school-age children: Links with social competence and sociometric status. Child Development, 66, 1385-1402.

Ryan, R. M., \& Lynch, J. H. (1989). Emotional autonomy versus detachment: Revisiting the vicissitudes of adolescence and young adulthood. Child Development, 60, 340-356.

Ryan, R. M., Stiller, J. D., \& Lynch, J. H. (1994). Representations of relationships to teachers, parents, and friends as predictors of academic motivation and selfesteem. Journal of Early Adolescence, 14, 226-249.

Sandler, J., \& Rosenblatt, B. (1962). The concept of the representational world. The Psychoanalytic Study of the Child, 17, 128-145.

Segal, Z. V., \& Blatt, S. J. (Eds.) (1993). The self in emotional distress: Cognitive and psychodynamic perspectives. New York: Guilford Press.

Segal, H. G., Westen, D., Lohr, N. E., \& Silk, K. R. (1993). Clinical assessment of object relations and social cognition using stories told to the picture arrangement subtest of the WAIS-R. Journal of Personality Assessment, 61, $58-80$.

Shields, A., Ryan, R. M., \& Cicchetti, D. (2001). Narrative representations of caregivers and emotion disregulation as predictors of maltreated children's rejection by peers. Developmental Psychology, 37, 321-337.

Shrout, P. E., \& Fleiss, J. L. (1979). Intraclass correlations: Uses in assessing rater reliability. Psychological Bulletin, 86, 420-428.

Sroufe, L. A. (1990). An organizational perspective on the self. In D. Cicchetti \& M. Beeghly (Eds.), The self in transition: Infancy to childhood (pp. 51-71). New York: Cambridge Universtiy Press.

Stern, D. (1985). The interpersonal world of the infant. New York: Basic Books.

Tinsley, H. E. A., \& Tinsley, D. J. (1987). Uses of factor analysis in counseling psychology research. Journal of Counseling Psychology, 34, 414-424.

Toth, S. L., \& Cicchetti, D. (1996). Patterns of relatedness, depressive symptomatology, and perceived competence in maltreated children. Journal of Consulting and Clinical Psychology, 64, 32-41.

Toth, S. L., Cicchetti, D., Macfie, J., \& Emde, R. N. (1997). Representations of self and other in the narratives of neglected, physically abused, and sexually abused preschoolers. Development and Psychopathology, 9, 781-796.

Van Ijzendoorn, M. H., \& Bakermans-Kranenburg, M. J. (1996). Attachment representations in mothers, fathers, adolescents, and clinical groups: A metaanalytic search for normative data. Journal of Consulting and Clinical Psychology, 64, 8-21.

Westen, D., Klepsen, J., Ruffins, S. A., Silverman, M., Lifton, N., \& Boekamp, J. (1991). Object relations in childhood and adolescence: The development of working representations. Journal of Consulting and Clinical Psychology, 59, 400-409.

Zilber, N., Auerbach, J., \& Lerner, Y. (1994). Israeli norms for the Achenbach Child Behavior Checklist: Comparison of clinically-referred and non-referred children. Israel Journal of Psychiatry and Related Disciplines, 31, 5-12. 


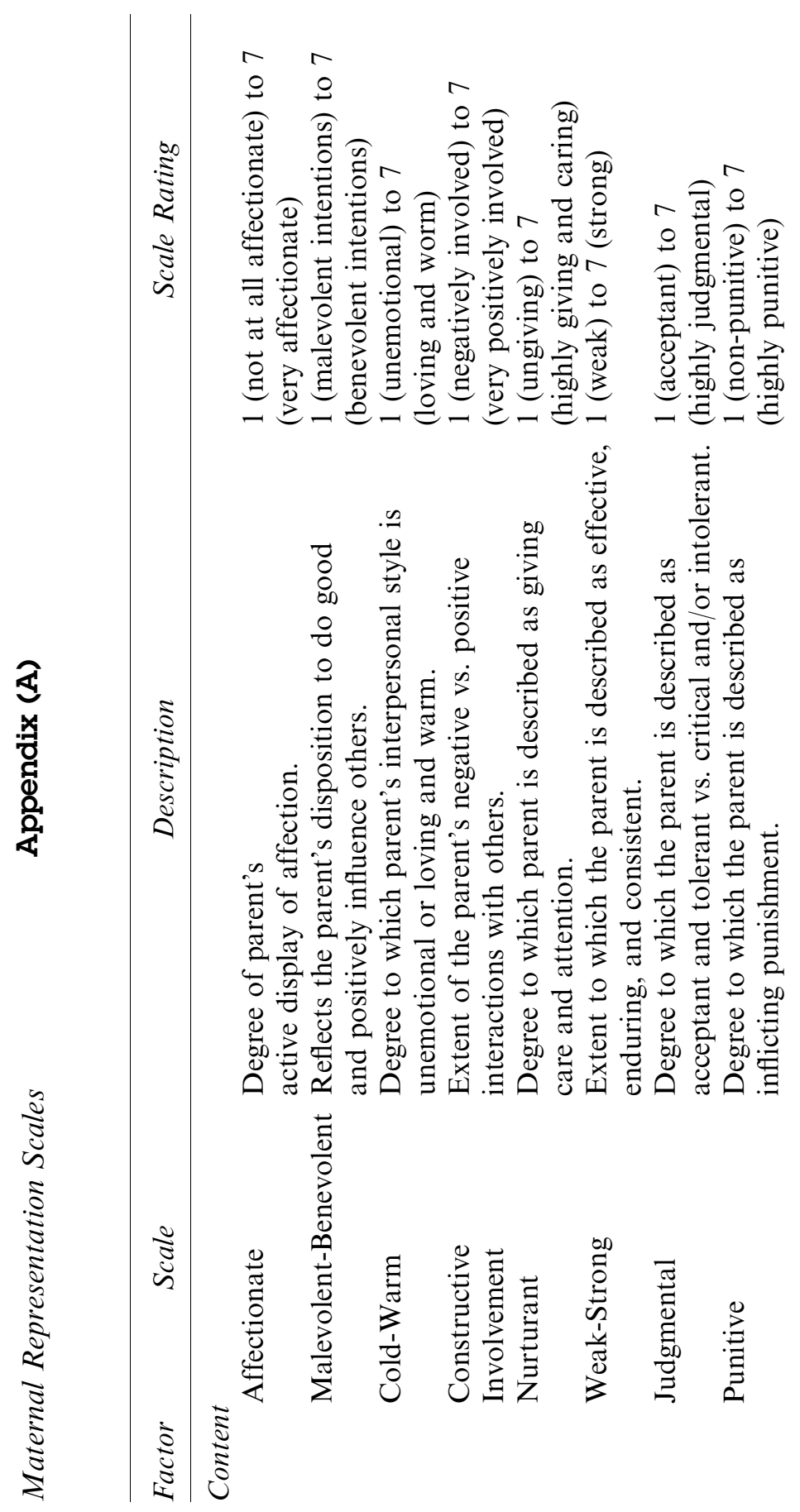




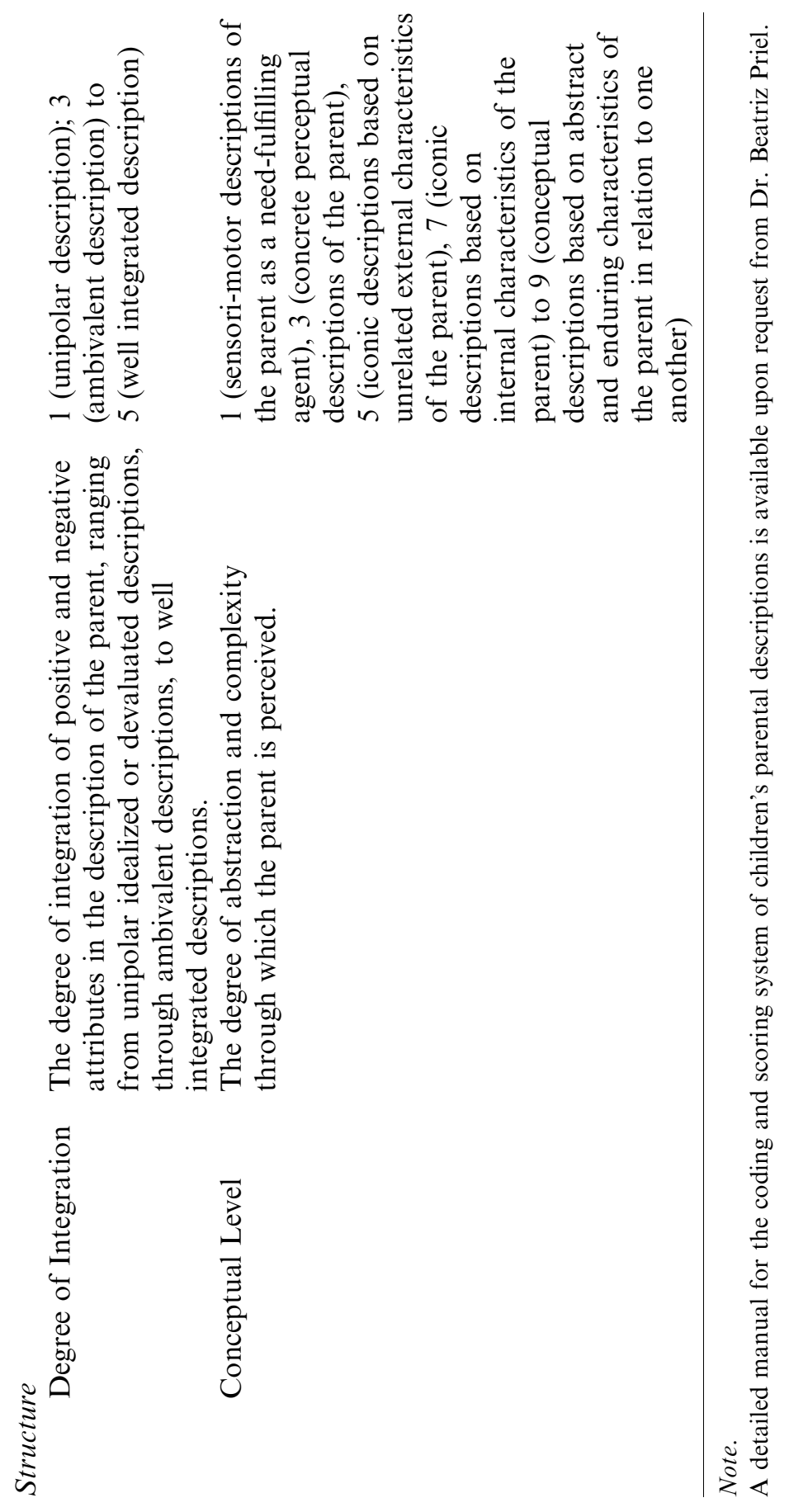




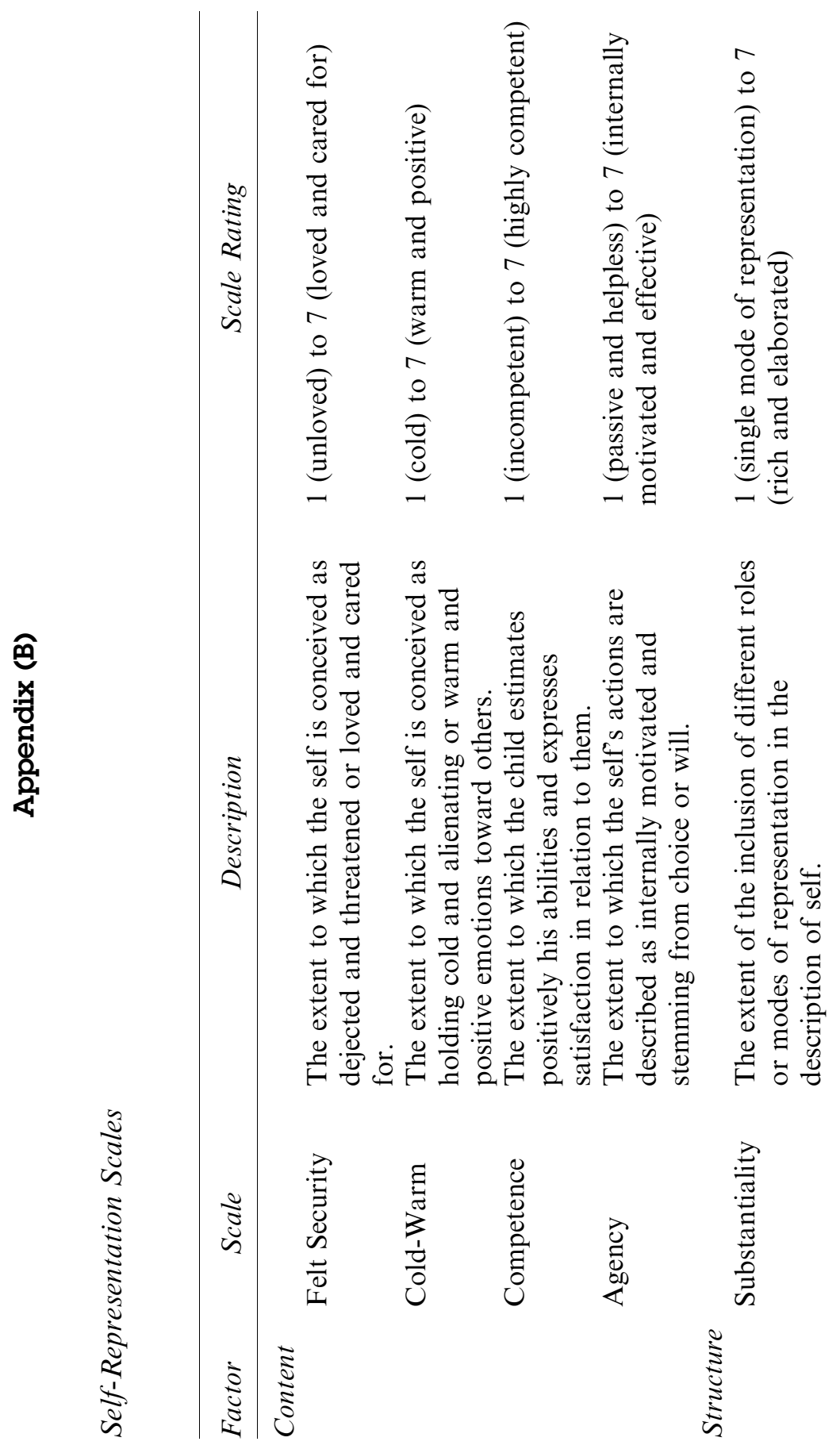




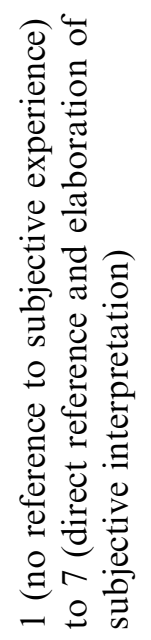

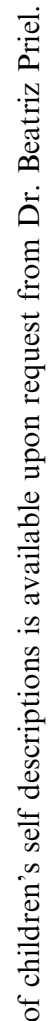

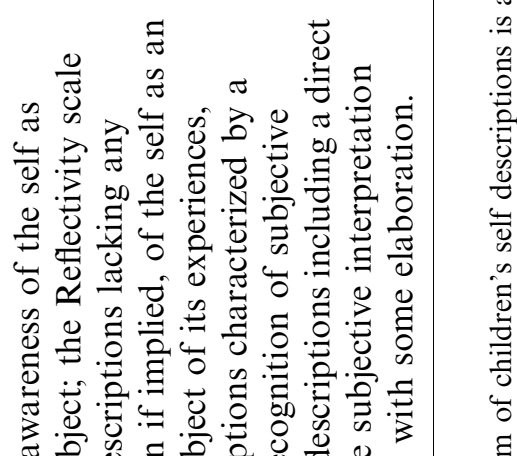

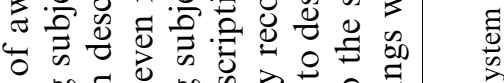
\&

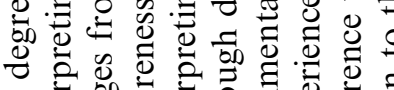
记 离

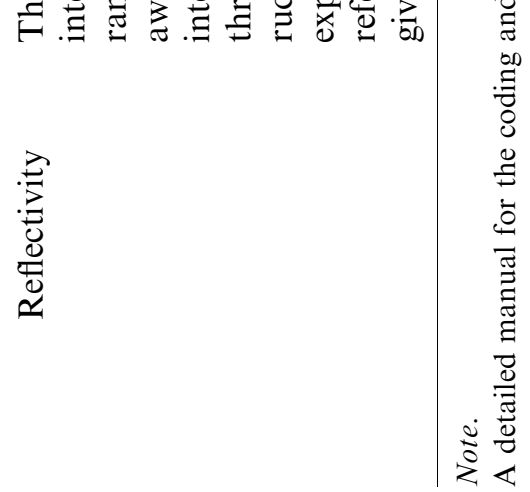


